\title{
INTERNET OF THING BASED CAR PARKING SYSTEM
}

\author{
SUNIL CHOUHAN, SANDHYA P
}

Department of ???, Vellore Institute of Technology, Chennai, Tamil Nadu, India. Email:asha.s@vit.ac.in Received: 23 January 2017, Revised and Accepted: 03 March 2017

\begin{abstract}
In the current era, we are facing a new problem of parking of vehicles. It is a major problem in urban cities. The problem is more tough because of continues growing number of vehicle and also size of vehicles. Car parking is not just a major problem in India but also in all over the world. We know that one million vehicles burn oil every day. In this paper, we propose an automatic and real-time system for automated car parking. This system would be implemented by the use of internet of things (IOTs). IOT refers as any physical thing that is connected to internet or exchanging information or data between internet and physical device. Arduino Uno is a microcontroller used in IOT. It is used for building digital devices, and interactive objects that can sense and control physical devices. Our smart parking will be implementing using Arduino Uno board for car parking and Ethernet shield to connect parking area with web or internet. By using our automated parking system, a user can save much time for searching free parking space. An infrared sensor has to be employed in each slot to check that a particular plot is vacant or not. Searching smart parking system helps people to search parking space accessible with the ease of IOT automation by supplying parking slot free information. The user can book in advance the parking slot and update the information to the server. Every user has a unique id and password. In case a car in stolen and enter the parking IOT the server checks the database and inform the police.
\end{abstract}

Keywords: Internet of things, Infrared sensor, Ethernet, Arduino Uno, RIFD.

(c) 2017 The Authors. Published by Innovare Academic Sciences Pvt Ltd. This is an open access article under the CC BY license (http://creativecommons. org/licenses/by/4. 0/) DOI: http://dx.doi.org/10.22159/ajpcr.2017.v10s1.19577

\section{INTRODUCTION}

Internet of things (IOTs) is a recent topic that plays an important role in our daily lives. IOT reduces human labor, effort, time and errors due to human negligence. With the development of modern technology, smartphones have become a necessity for every person on this planet. A smart parking system helps to monitor vehicle parking. It helps to manage parking collision among vehicles when they are parking at the same time that means it helps in synchronized parking. In IOT objects are connected to each other and exchange information from internet. Our IOT based smart parking organized the parking lot. It helps user to find a free space in parking slot. It saves user's time as well as their fuel. It helps nowadays to obtain parking spaces in metropolitan area which is very crucial. People waste money and fuel in searching for parking lot. Smart parking system gives information about parking spaces. An infrared (IR) sensor is used at each slot in parking; it tells the space availability. The information about the free or used slot sends over web page through IOT. Furthermore, we have other IOT platform like home automation, heart monitoring, any physical thing that is connected and exchanging information from internet. At present, Cisco is working very hard on IOT and probably up to year 2020 every appliance will be controlled by internet. Due to continue the growth of vehicle, it is difficult to find a parking place in a short amount of time and also it wasted a lot of fuel in searching an empty parking place. Hence, to overcome from this serious problem, we are implementing an automated parking where it can tell to user that parking space is available or not for his car. If slot is empty, they can go otherwise need search a new place instead of go and search for parking. In metropolitan area, smart car parking system becomes major point with rise numbers of vehicles. Normally, it takes more than 10 minutes to find parking space. This increases wastage of fuel, time and money. To control these limitations smart parking system using IOT based mobile application is proposed. It used global system for mobile communication/general packet radio service technology to overcome these limitations [7,8]. Anisotropic magneto-resistive sensors are used to obtain correct availability of parking slot (Fig. 1).

\section{LITERATURE REVIEW}

Paper [1,6] proposed a new algorithm for planning in real-time parking. The parking scheduling is converted into an off-line problem. The off- line problem is described as a linear problem. The linear problem was solved using an algorithm. Finally, experimental simulations were done. However, this paper does not deal with the guiding of vehicles. Paper [2] proposes a solution for parking lot based on wireless sensor network and radio-frequency identification (RFID). The paper [2] however does not deal with a large scale parking lot. Paper [3] has proposed a parking system based on ZigBee network. Here, a web service is used to collect information about the parking space. Our approach is based on 8051 type microcontroller that is Arduino microcontroller, Arduino runs with Arduino IDE application that should be installed in system. We do simple embedded C code in microcontroller and directly put it into the Arduino system. We do simple embedded C code in microcontroller and directly put it into the Arduino microcontroller. Hence, it works according to code system keeps track of number of cars entered in parking building. The counting will be display using liquid crystal display board and IR sensor that sense the cars standing in front of parking gate.

\section{PROPOSED SYSTEM}

The proposed system is based on IOT. The parking lots are monitored using RFID. The user can log on to the parking application and determine the free slot. In our paper, we determine the car parking lot that is nearest to the user. In case the parking lot is full then the system will also guide the user to the next nearest car park. The system architecture is described in Fig. 2.

The system architecture is based on Arduino Uno microcontroller board, Ethernet shield, IR sensor, RFID and car parking on/off system.

\section{ARDUINO}

The Arduino Uno is a microcontroller board [4,5]. It is used ATmega328p. Arduino Uno have 14 input/output pins and output pin (PMW outputs as of which 6 can be used) and 6 analog inputs. The Arduino Uno circuit acts as an interface between the software part and the hardware part of the project. Arduino board is one type of microcontroller. It is able to read input like light sensor, detect motion and gives an appropriate output on it. Arduino works like a brain so here we can store programs code. Also in the Ethernet shield, we have a memory card where we can 
store lots of internet data. This board connected with an Ethernet cable with a standard RJ-45 connection and the micro SD card can be read from the SD library (Fig. 3).

\section{Ethernet shield}

Ethernet shield it is used for connecting Arduino to internet. This shield allows us to exchange data worldwide through the internet connection. We can use this stuff in controlling the robot or many things with a speed of 10/100 MB. It comes under Arduino Ethernet library (Fig. 4).

\section{Car parking turn-off system}

Car parking turn-off system evolves peripherals same as car parking turn-on system. We are having two light-emitting diodes (LEDs). If the user takes left then LED green turned and if user takes right then red LED turned off. We are having RFID technology radio frequency identification it is used to identify owner details, car number, car ID,

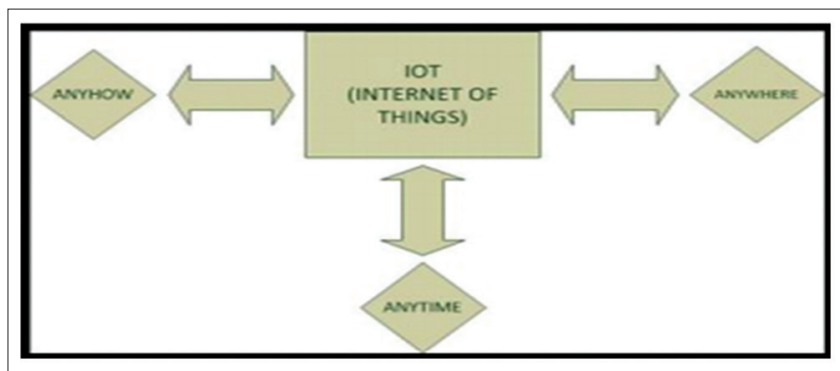

Fig. 1: Internet of things [11]

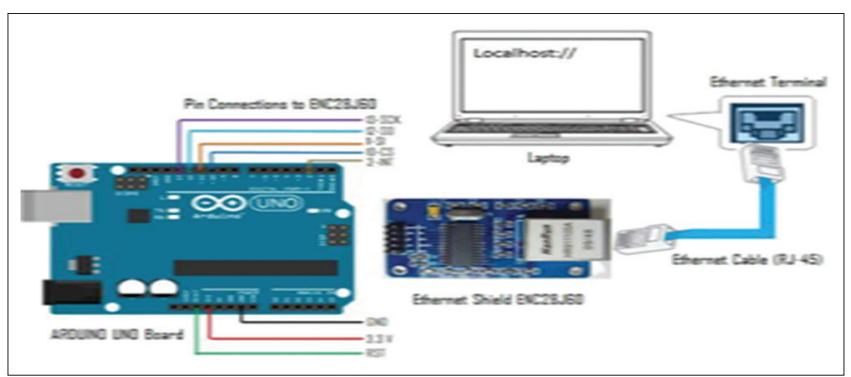

Fig. 2: System architecture

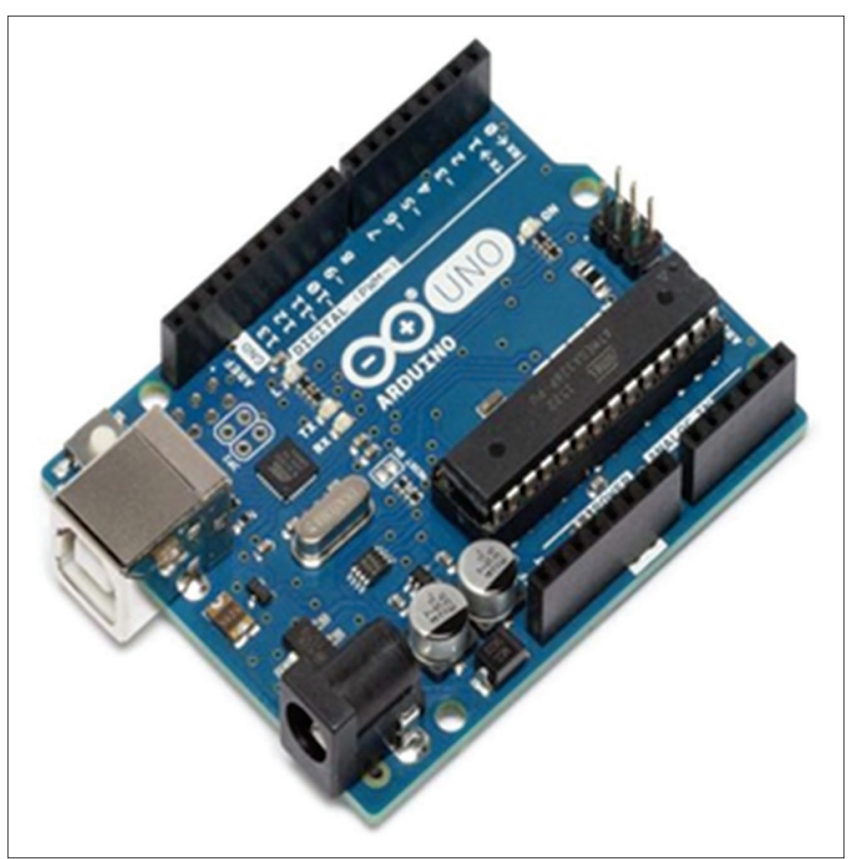

Fig. 3: Arduino Uno and so on.

\section{IR SENSOR}

An IR sensor is an electronic device that emits to sense some aspects of the surroundings. An IR sensor can measure the heat of an object as well as detects the motion. These types of sensors measure only IR radiation rather than emitting it, that is called as a passive IR sensor (Fig. 5).

\section{Car parking system using cloud server}

Cloud storage is a cloud computing model, in which data is stored on remote servers accessed from the internet, or "cloud" [9]. It is maintained, operated and managed by a cloud storage service provider on storage servers that are built on virtualization techniques. For some computer owners, finding enough storage space to hold all the data they've acquired is a real challenge. Some people invest in larger hard drives. Others prefer external storage devices like thumb drives or compact discs. Desperate computer owners might delete entire folders worth of old files to make space for new information. However, some are choosing to rely on a growing trend: Cloud storage.

\section{Guiding system to the nearest car park}

In this paper, we find the nearest parking lot by considering the set of parking lots as a network [10]. Each node in the network is the parking lot. The RFID detects if the parking lot is full or empty. If it is empty, then the status is set as counter +1 in the status table. The status table has the list of direct neighboring nodes and their distances from the current node. It also maintains the counter for vacancy in each neighboring car park. The distances are sorted in ascending order for all the neighboring parking lots with counter $>1$. The parking lot with

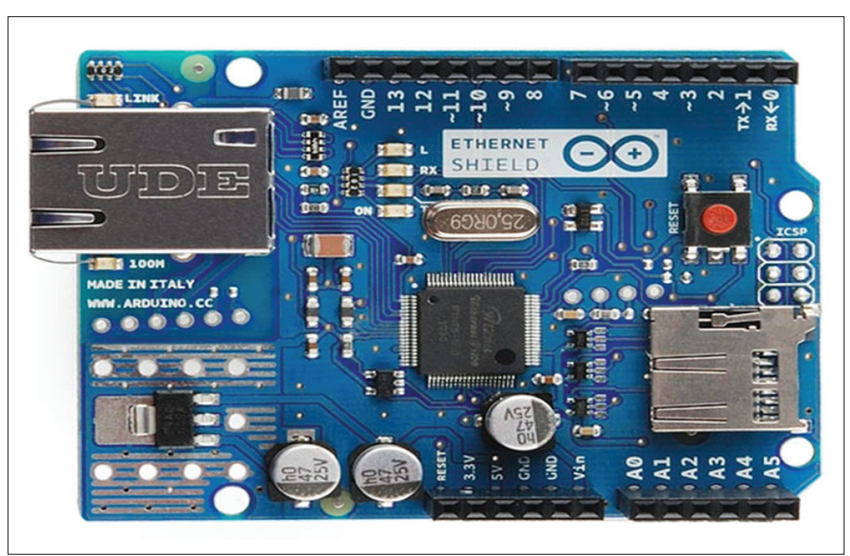

Fig. 4: Ethernet shield

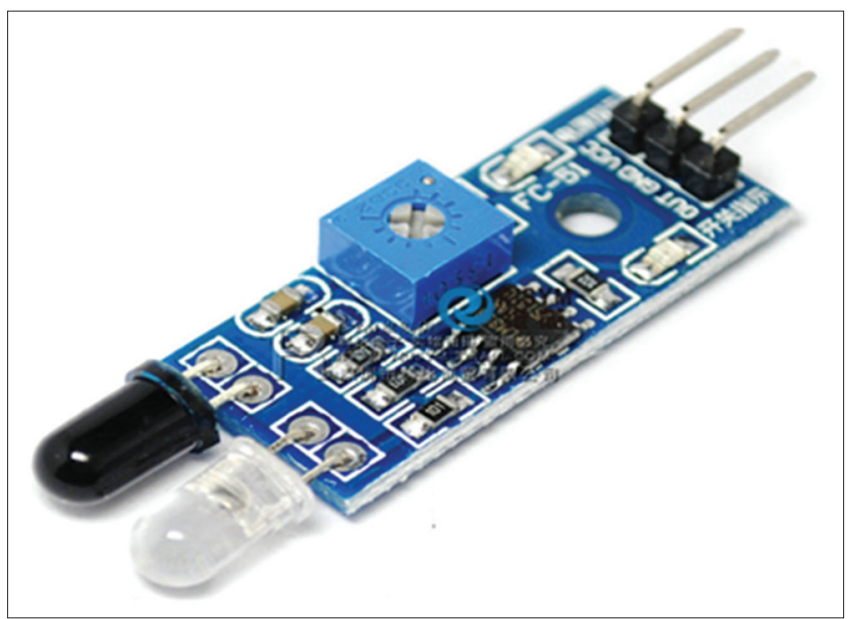

Fig. 5: Infrared sensor 


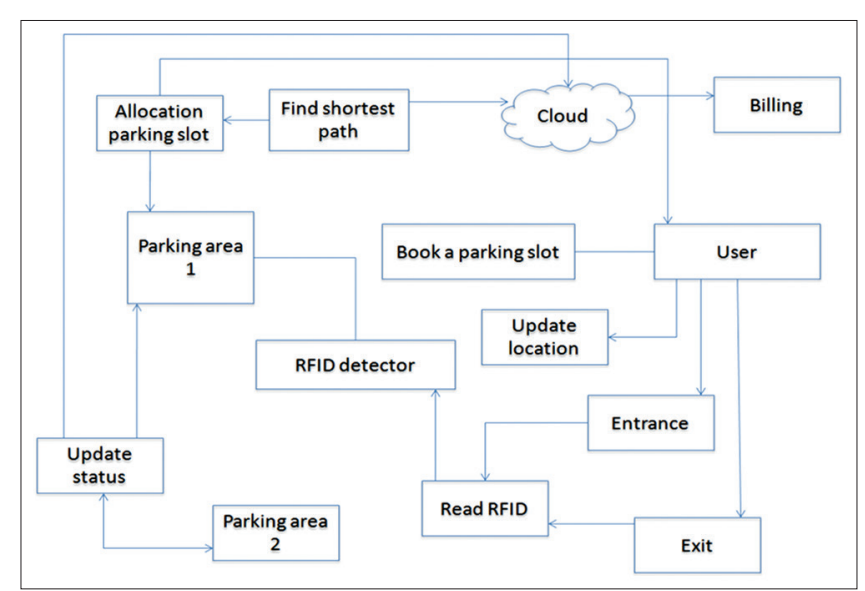

Fig. 6: System modules

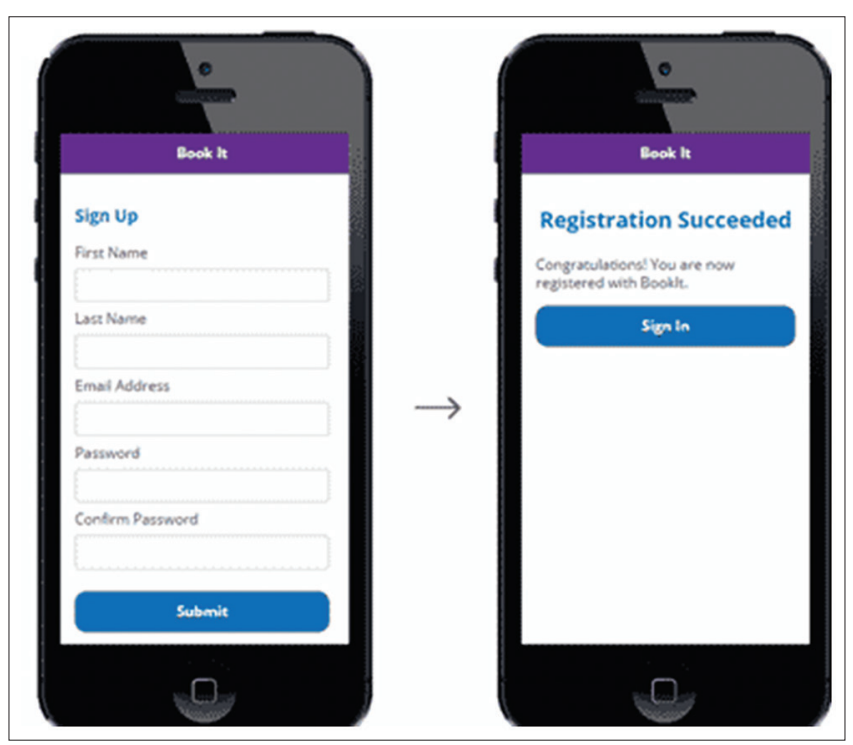

Fig. 7: Login page

the minimum distance and counter $>1$ is selected for booking. Once the parking lot is booked the counter of that parking lot is decreased by one. Whenever there are changes in the counter, it is updated in the server (Fig. 6).

\section{ANDROID APPLICATION}

Android is the mobile operating system and it has own operating apps and android software development kit primarily written in Java programming language. We can create our own apps and also we can install in our mobile anyone can use these apps after the registration is completed. User can download the android app for booking parking slot. User booking parking space is implemented through the android app (Fig. 7).

\section{Payment system}

In metropolitan areas searching parking, slot is very critical in peak hours. In our system, user can book the parking slot in advance like theatre tickets booking online by mobile phone. We can book parking spaces by mobile apps and websites. The IOT database gives information availability of parking slot. The user can pay fee by mobile phone or ATM Sever can automatically update status after finished payment (Fig. 8).

\section{Implementation}

Arduino with the Ethernet shield for PC configuration of the physical address is mandatory. For Ethernet shield, IP address is user defined if both IP address match. Hence, our hardware module will interact

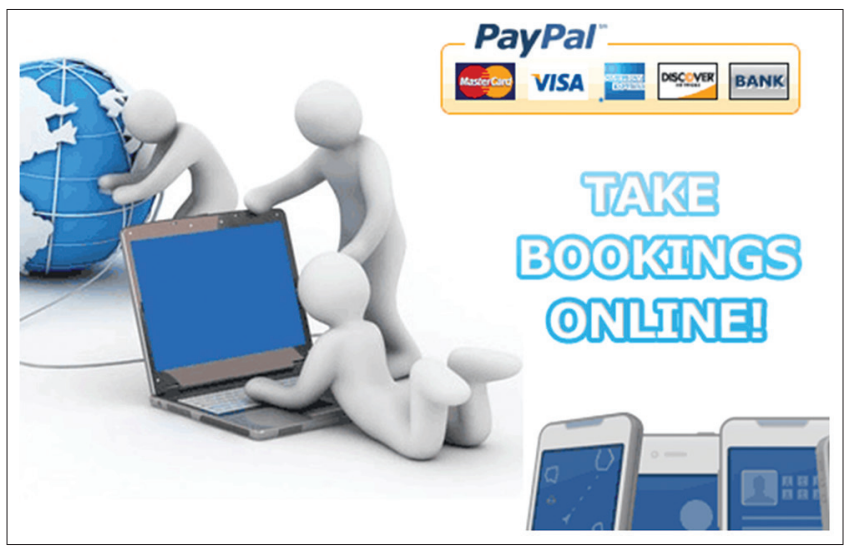

Fig. 8: Online payment

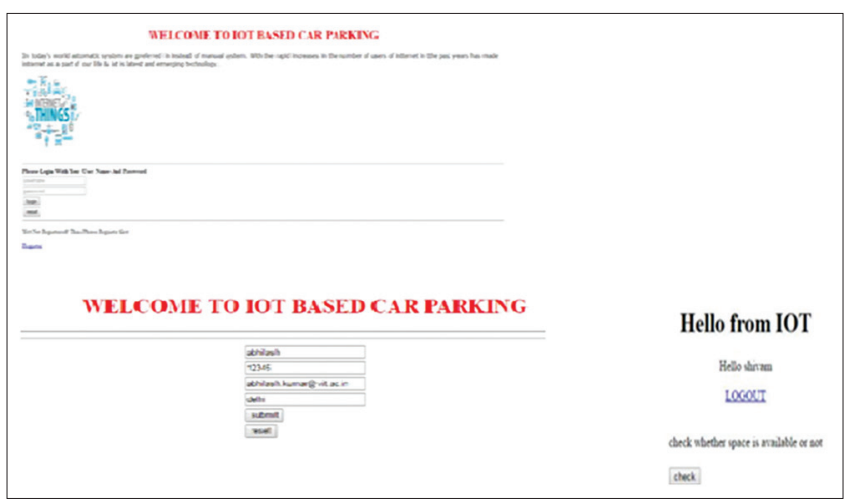

Fig. 9: Webportal

with PC. So next time a user can login or register with his authorized ID and password. Here are some login snapshots. So, a user can check for available space in the parking slot. Here, we have some snapshots of IOT based car parking. The concept is to improve making the car parking easy, workable; therefore, we developed smart car parking system (Fig. 9).

\section{CONCLUSION}

From the proposed IOT based car parking, any passenger can register and login with his appropriate user id and password and then check for space availability of parking IOT. If space is available there, he will be allowed to go inside the parking IOT. A user can login and check for free space from anywhere which is the objective of car parking system using IOT. By using IOT, we can access information using internet. Nowadays, every person having a smart mobile phone uses internet. Hence, smart car parking system provides facility to book place for parking and it provides facility for user to pay fee online. Smart car parking uses RFID. It is used to detect and identify owner name, address and so on. Smart parking system it is used for minimizing manpower as well as fuel. The enhancement of the paper is to consider the traffic in the path of various car parks.

\section{REFERENCES}

1. Geng Y, Cassandras CG. A new smart parking system based on optimal resource allocation and reservations. In: Proceeding of $14^{\text {th }}$ International IEEE Conference on Intelligent Transportation Systems; 2011. p. 979-84.

2. Geng Y, Cassandras CG. New smart parking system based on resource allocation and reservations. IEEE trans Intell Transp Syst 2013;14(3):1129-39.

3. Shiyao C, Ming W, Chen L, Na R. The research and implement of the intelligent parking reservation management system based on ZigBee technology. Proceeding $6^{\text {th }}$ International Conference on Mechatronics and Automation Technology Mechatronics Automation. (ICMTMA); 2014. p. 741-4.

4. Sen S, Chakrabarty S, Toshniwal R, Bhaumik A. Design of an 
intelligent voice controlled home automation system. Int J Comput Appl 2015;121(15):39-42.

5. Gandhi BM, Rao K. A prototype for IOT based car parking management system for smart cities. Indian J Sci Technol 2016;9(17). DOI: 10.17485/ijst/2016/v9i17/92973.

6. Vishwanath Y, Kuchalli AD, Rakshit D. Survey paper on smart parking system based on internet of things. Int J Recent Trends Eng Res 2016;2(3):156-60.

7. He W, Yan G, Xu LD. Developing vehicular data cloud services in the
IOT environment. IEEE Trans Ind Inform 2014;10(2):1587-95.

8. Basavaraju SR. Automatic smart parking system using internet of things (IOT). Int J Sci Res Publ 2015;5(12):629-32.

9. Pham TN, Tsai MF, Nguyen DB, Dow CR, Deng DJ. A cloud-based smart-parking system based on internet-of-things technologies. IEEE Access 2015;3:1581-91

10. Ichake VD, Shitole PD, Momin M, Thakare KS. Smart car parking system based on IOT concept. Int J Eng Sci Invent 2016;5(3):48-54. 